\title{
THE RESULTS OF PLATING HUMERAL SHAFT FRACTURES IN PATIENTS WITH MULTIPLE INJURIES
}

\author{
THE SUNNYBROOK EXPERIENCE
}

\author{
M. J. BELl, C. G. BEAUChAMP, J. K. KEllaM, R. Y. MCMURTRY
}

From the Sunnybrook Medical Centre, Toronto

\begin{abstract}
Excellent results can be achieved by plating fractures of the shaft of the humerus in patients with multiple injuries. This helps in nursing care and in the management of other injuries. In 38 patients admitted to a regional trauma centre, 39 humeral shaft fractures were plated. There were 27 men and 11 women, with an average age of 31.5 years. Fourteen of the humeral fractures were compound and 20 had significant comminution; 23 were fixed by a plate on the day of admission and all 39 by the twentieth day.

Follow-up of 34 fractures showed that all had united, 33 primarily. All patients but one had a fully functional shoulder and no patient with a fractured humerus alone had lost any elbow movement. Complications were rare - one case each of non-union, fixation failure and infection. No permanent nerve injuries were produced at operation. The plating of fractures of the humerus in these circumstances has been shown to produce excellent results and has a place in the management of the patient with multiple injuries.
\end{abstract}

It is generally accepted that conservative management is best for isolated closed fractures of the shaft of the humerus (Bohler 1965; Klenerman 1966; Christensen 1967; Rüedi et al. 1974; Sarmiento et al. 1977). However, there are circumstances when internal fixation of such fractures may be indicated, namely for open fractures with nerve injury, for fractures associated with vascular injury, for fractures extending into neighbouring joints, for bilateral fractures and for the patient with multiple injuries (Rüedi et al. 1974; Mast et al. 1975).

There are few reports on the results of internal fixation of fractures of the humeral shaft and none on internal fixation in the patient with multiple injuries. Vichare (1972) found that standard conservative methods of treatment in such patients led to a high incidence of malunion and non-union; he devised a traction system to overcome the problem. However, an important aim in the management of these patients is to be able to sit them upright with painfree extremities (McMurtry and Pickard 1980). Failing this, prolonged recumbency may lead to considerable morbidity. Inter-

M. J. Bell, BSc, MB BS, FRCS, Senior Orthopaedic Registrar Royal Hallamshire Hospital, Glossop Road, Sheffield S10 2JF, England.

C. G. Beauchamp, MB ChB, FRCS, Senior Orthopaedic Registrar Queen's Medical Centre, Nottingham NG7 2UH, England.

J. F. Kellam, MD, FRCS(C), Consultant Orthopaedic Surgeon R. Y. McMurtry, MD, FRCS(C), FACS, Director

Regional Trauma Unit, Sunnybrook Medical Centre, 2075 Bayview Avenue, Toronto, Ontario, Canada M4N 3M5.

Requests for reprints should be sent to Dr R. Y. McMurtry.

(C) 1985 British Editorial Society of Bone and Joint Surgery $0301-620 \mathrm{X} / 85 / 2043 \$ 2.00$ nal fixation of fractures of the humerus allows ready access for nursing care, since restrictive bandages and splints are avoided. Early mobilisation of the limb helps to prevent the "fracture disease" (Müller et al. 1979).

This paper will show that the plating of humeral shaft fractures allows for better management of the multiply injured patient, and that it can provide a mobile, painfree extremity, with reliable union of the fracture and excellent function.

\section{MATERIAL AND METHODS}

The Regional Trauma Unit at Sunnybrook Medical Centre, Toronto, opened in 1976, and up to October 1983, 1559 seriously injured patients had been admitted. Of these, 38 had sustained 39 fractures of the humeral shaft which had been treated by internal fixation with a plate. A fracture of the humeral shaft is defined as one occurring below the surgical neck and above the supracondylar ridge of the humerus.

The cause of the injuries leading to admission was a motor-vehicle accident in 28 , a pedestrian injury in three, a fall in three and other causes in four. There were 27 men and 11 women with an average age of 31.5 years and with an Injury Severity Score (Baker et al. 1974; Baker and O'Neill 1976) ranging from 13 to 45, average 27.5. The site of injury to the shaft of the humerus was the upper third in 15, the middle third in 15 and the lower third in nine. Twenty fractures had significant comminution and 14 were compound, of which nine were Grade I, four were Grade II and one Grade III (Chapman and Hansen 1984). Twelve had associated 
Table I. Major injuries sustained by 38 patients with fractures of the shaft of the humerus treated by plating

\begin{tabular}{|c|c|c|}
\hline Head injury & 26 & $\begin{array}{l}\text { Skull fracture } \\
\text { Facial fracture } \\
\text { Cerebral oedema } \\
\text { Intracranial bleeding } \\
\text { CSF leak }\end{array}$ \\
\hline Chest injury & 26 & $\begin{array}{l}\text { Lung contusion } \\
\text { Rib fracture } \\
\text { Flail chest } \\
\text { Pneumothorax }\end{array}$ \\
\hline Abdominal injury & 7 & $\begin{array}{l}\text { Liver laceration } \\
\text { Bowel tear } \\
\text { Ruptured spleen } \\
\text { Bladder tear }\end{array}$ \\
\hline $\begin{array}{l}\text { Other fractures } \\
\text { (pelvis, legs and opposite } \\
\text { arm) }\end{array}$ & 52 & $\begin{array}{l}\text { Pelvis } \\
\text { Femur } \\
\text { Tibia } \\
\text { Forearm } \\
\text { Wrist } \\
\text { Knee } \\
\text { Elbow } \\
\text { Ankle } \\
\text { Foot }\end{array}$ \\
\hline
\end{tabular}

nerve injuries which were identified before operation; the radial nerve was involved in eight, and the posterior interosseous nerve in two, both of which also had forearm fractures; there were two brachial plexus lesions.

Other injuries suffered by these 38 patients are listed in Table I, as are significant fractures of the other three limbs. Fifteen of the patients had a total of 22 fractures or joint injuries in the same limb as the fractured humerus.

Twenty-three patients had internal fixation of their humeral fractures on the first day after injury, and all had their fractures plated by the twentieth day. Primary bone grafting was performed in seven cases, and five had delayed grafting, up to 26 days after fixation of the fracture. All the fractures were exposed by the antero- lateral approach of Henry (1973), which was extended along the deltopectoral groove to obtain access to fractures of the proximal third.

Compound fractures were managed in the same way; they had open reduction and internal fixation, but the wounds were left open. When the wound was clean and healthy it was closed by delayed primary closure or by skin grafting.

\section{RESULTS}

Full follow-up was available for 33 patients with 34 fractures of the humerus. All but one of the fractures united primarily, as defined by disappearance of the fracture line (Figs 1 and 2). The average time to union was 19 weeks. Proximal third fractures healed sooner than those of the middle and lower thirds, the mean times being 14, 23 and 19 weeks respectively. Six fractures took six months or longer to unite, the longest taking one year.

There were three significant complications. In one patient screws cut out of the bone two weeks after plating; the fracture waas replated and grafted, and union took place in four months (Figs 3 and 4). In the one case of non-union the plate fractured 18 months after injury (Fig. 5); the plate was removed and the humeral fracture replated and grafted, with subsequent union. There was one case of infection, which resulted in loosening of the fixation; despite this, union took place at 22 weeks, but with 20 varus angulation at the fracture site. The infection, treated with antibiotics, resolved with no persisting osteomyelitis, and the plate was removed later. This patient originally had open femoral fractures, a head injury and a compound facial injury and we believe it was from the facial injury that the haematogenous infection of the humeral fracture occurred.

All but one of the eight radial nerve palsies re-

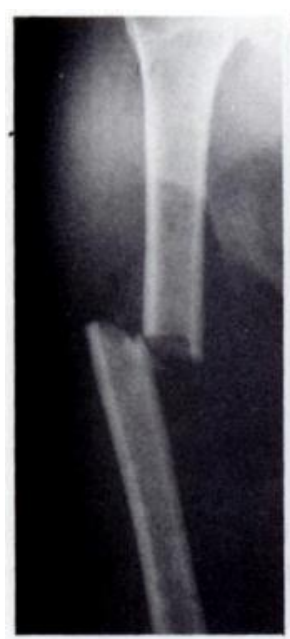

Fig. 1

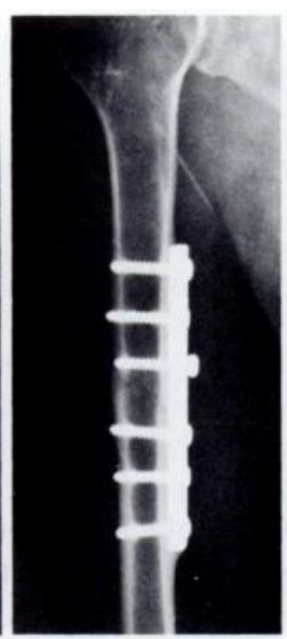

Fig. 2

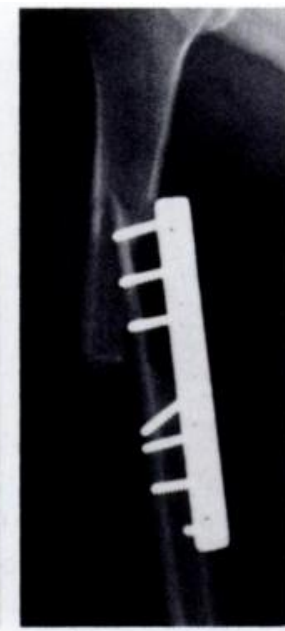

Fig. 3

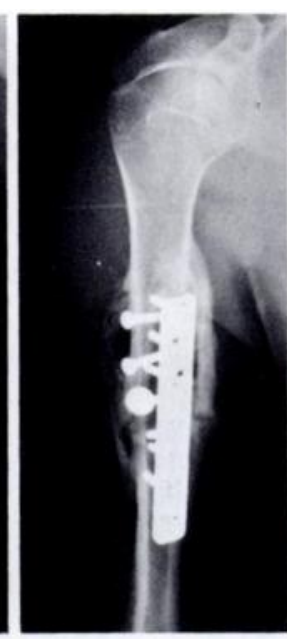

Fig. 4

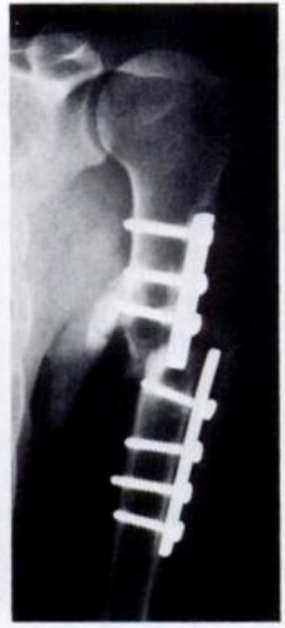

Fig. 5

Figures 1 and 2-A transverse fracture of the shaft of the humerus which united after plating, with disappearance of the fracture line. Figures 3 and 4 Failure of fixation at two weeks, and the satisfactory end-result after replating. compression screws and bone grafts. Figure 5-Non-union with fracture of the plate through a screw hole 18 months after injury. Union was obtained after replating and bone grafting. 
covered; that patient required tendon transfers one year after injury. Both cases of posterior interosseous nerve injury recovered fully as did one of the brachial plexus lesions. The other case of brachial plexus injury had a complete $\mathrm{C} 6$ to $\mathrm{T} 1$ loss and had an amputation 18 months after the accident. One radial nerve palsy first appeared after operation and recovered within one week. Another patient developed a delayed ulnar nerve paresis which was not apparent before or immediately after operation. This was thought to be due to pressure on the ulnar nerve at the elbow during postoperative recovery.

A fully functional shoulder was restored in all but one patient, 26 regaining a normal range of movement, though four lost up to 15 rotation and three lost some abduction. The loss of these few degrees of range of movement has not resulted in impaired function. One patient with significant limitation had a Grade III compound fracture from a shotgun injury; most of the deltoid was damaged and the patient now has only 100 of combined abduction. No patient with a humeral shaft fracture alone lost any elbow movement and only the three patients who had severe elbow injuries in addition to fracture of the humerus lost flexion, extension or rotation at the elbow (Figs 6 and 7).

\section{DISCUSSION}

A number of reports discuss the internal fixation of fractures of the humeral sh 'ft (Christensen 1967; Rüedi et al. 1974; Titze 1974; Durbin, Gottesman and Saunders 1983), but no author has reported specifically on the results in patients with multiple severe injuries. Rüedi et al. (1974), Titze (1974) and Durbin et al. (1983) consider that these patients have one of the definite indications for internal fixation of this fracture.

The aim of fixation is to obtain an upright patient with painfree extremities. Table I shows that these patients had a large number of other injuries which would require intensive nursing care. The use of U-slabs, hanging casts, gutter splints and body bandages is quite inappropriate in this setting. Vichare (1972) described the use of a traction system but this also is ill-suited for use in the intensive care unit. Internal fixation facilitates better nursing care and helps to avoid forced recumbency.

Having recommended internal fixation for fractures of the humeral shaft in these patients, is plating a suitable method? The objections which have been made to humeral shaft plating are that it may lead to non-union (Gartland et al. 1959), or to radial nerve injury (Bohler 1965; Titze 1974) or to infection, or that the fixation may fail with refracture through the screw holes (Rüedi et al. 1974). The present series showed few problems, with only three cases of significant complications.

Thirty-three of 34 fractures united primarily, a rate of union which is as good or better than that reported for isolated closed fractures treated conservatively (Gartland et al. 1959; Holm 1970). The time to union is

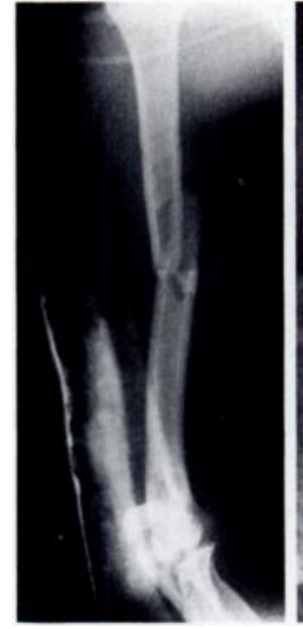

Fig. 6

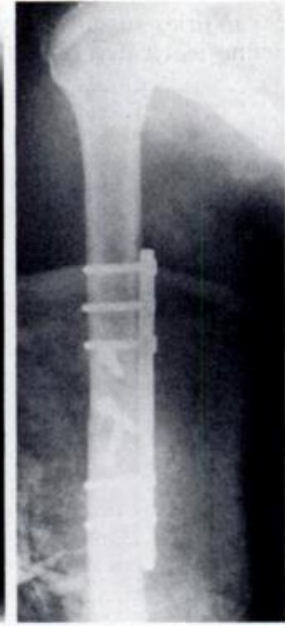

Fig. 7
Fracture of the humerus with associated fractures of the ulna and the capitellum. After operation there is good fixation of the humeral fracture and the elbow can be treated independently.

longer than that reported for conservative treatment (Klenerman 1966), but the high energy of the initial violence, leading to considerable soft-tissue damage and fracture comminution, is an important consideration. And even though the fractures appeared to join slowly, the patients were often able to use the arm without external splinting from the first week after operation. This early use helps prevent the osteoporosis, muscle atrophy, joint stiffness and limb oedema of the "fracture disease" (Müller et al. 1979). The excellent functional results, with only one case of significant limitation of shoulder movement, as well as the rate of union, support the view that internal fixation followed by early movement is better for the patient and for the fracture.

Seddon (1975) stated that $70 \%$ of radial nerve injuries associated with humeral shaft fractures will recover; the recovery rate in our series was $87.5 \%$. In two cases at operation the nerve was found to have been spiked by a bone fragment. In these two at least, the open reduction reduced any further damage to the nerve, and this factor may account for the good rate of recovery. Radial nerve injury at operation can be avoided if close attention is paid to surgical technique; this is supported by our having only one transient nerve lesion. The radial nerve should be identified above and below the fracture and held away from the dissection by gentle traction.

There was no problem with infection in our patients, despite the treatment of open fractures with early internal fixation. Internal fixation per se does not increase the incidence of wound or bone infection. After fixation of compound fractures the wounds should be left open and closed later by delayed primary methods or, if necessary, by skin grafting.

The failure of fixation at two weeks in one case was due to poor technique, with an inadequate hold; when the fracture was replated with the addition of three 
interfragmentary compression screws and a bone graft, the fracture united in four months without complication.

One aim in the management of the patient with multiple injuries is to achieve an upright position with painfree extremities. The early plating of humeral shaft fractures helps to attain this goal, and also helps to prevent the "fracture disease" by allowing early mobilisation. The excellent return of function, the reliable progression to union and the minimal morbidity support the view that the plating of fractures of the humeral shaft in these patients is not only better for the patient but also better for the fracture.

\section{REFERENCES}

Baker SP, O'Neill B, Haddon W, Long WB. The Injury Severity Score: a method for describing patients with multiple injuries and evaluating emergency care. J Trauma 1974;14:187-96.

Baker SP, O'Neill B. The Injury Severity Score: an update. J Trauma $1976 ; 16: 882-5$.

Bohler $\mathbf{L}$. Conservative treatment of fresh closed fractures of the shaft of the humerus. $J$ Trauma 1965:5:464-8.

Chapman MW, Hansen ST Jr. Current concepts in the management of open fractures. In: Rockwood CA. Green DP, eds. Fractures in adults. 2nd ed. Philadelphia etc.: JB Lippincott, 1984;1:199-218.

Christensen S. Humeral shaft fractures, operative and conservative treatment. Acta Chir Scand 1967:133:455-60.
Durbin RA, Gottesman MJ, Saunders KC. Hackethal stacked nailing of humeral shaft fractures: experience with 30 patients. Clin Orthop 1983:179:168-74.

Gartland JJ, Ferguson AB Jr, Goodman MC, Rodriguez EE, Skovrou M. Fresh midshaft fractures of the humerus in adults: evaluation of treatment in Pennsylvania during 1952-1956. made by the Scientific Research Committee. Pennsylvania Orthopedic Society. Penn Med J 1959:52:848.

Henry AK. Extensile exposure. 2nd ed. Edinburgh, London: Churchill Livingstone 1973.

Holm CL. Management of humeral shaft fractures: fundamental nonoperative technics. Clin Orthop 1970:71:132-9.

Klenerman L. Fractures of the shaft of the humerus. J Bone Joint Surg [Br] 1966:48-B: 105-11.

Mast JW, Spiegel PG, Harvey JP Jr, Harrison C. Fractures of the humeral shaft: a retrospective study of 240 adult fractures. Clin Orthop 1975:112:254-62.

McMurtry RY, Pickard J. The multiply injured patient: a challenging orthopaedic nursing problem. Can Orthop Nurs Assoc J 1980; 3:2-5.

Müller ME, Allgöwer A, Schneider R, Willnegger H. Manual of internal fixation: techniques recommended by the AO group. 2nd ed. Berlin, Heidelberg, New York: Springer-Verlag, 1979.

Rüedi T, Moshfegh A, Pfeiffer KM, Allgöwer A. Fresh fractures of the shaft of the humerus: conservative or operative treatment? Reconstr Surg Traumatol 1974;14:65-74.

Sarmiento A, Kinman PB, Galvin EG, Schmitt RA, Phillips JG. Functional bracing of fractures of the shaft of the humerus. $J$ Bone Joint Surg $[\mathrm{Am}]$ 1977:59-A:596-601.

Seddon H. Surgical disorders of the peripheral nerves. 2nd ed. Edinburgh, London. New York: Churchill Livingstone. 1975.

Titze A. The operative treatment of fractures of the shaft of the humerus. Reconstr Surg Traumatol 1974;14:75-83.

Vichare NA. Fractures of the humeral shaft associated with multiple injuries. J Bone Joint Surg [Br] 1972;54-B: 175. 